\title{
External and Internal Neurolysis of Ulnar and Median Nerves in Leprous Neuritis ${ }^{*}$
}

\author{
GA LA L Z. SAID, A. ZOHDY and I. N. EL-AKKAD \\ Departments of Orthopaedic Surgery and Pharmacology, \\ Faculty of Medicine, Assiut University, Egypt
}

\begin{abstract}
Out of 36 cases of leprous neuritis treated by external and internal neurolysis of the ulnar and/or median nerve ( 17 bilateral), $91.2 \%$ of those followed-up cases were free from pain, $58.3 \%$ showed complete or partial clinical improvement of motor function, and $46.2 \%$ showed sensory improvement after the operation.

E.M.G. study of 8 cases of ulnar neuritis ( 6 bilateral) before and at varying intervals after the operation was performed. It showed marked or limited improvement of muscle action potentials in $64.3 \%$ of decompressed nerves.

Best results were obtained when the nerve trunk at operation showed hyperaemia of its sheath, oedema, and swelling. The worst results were noted in cases in which the nerve was thin, ischaemic, and fibrosed. Nerve abscess was encountered 5 times, 3 times in the ulnar nerve and twice in the median nerve.
\end{abstract}

In spite of the modern treatment of leprosy, neuritis sometimes supervenes. The persistent and continuous nagging pain which it causes adds much to the misery of leprous patients. In addition to the pain and paraesthesia, motor paralysis, deformity and trophic ulceration are the ultimate results in neglected cases.

Many attempts have been made to relieve the pain of leprous neuritis. Among the conservative measures tried are: peri- or intra-neural injection of hydrocortisone, lignocaine and hyalase (Jennings, 1964; Tio, 1966), the application of heat in the form of hot compresses, diathermy or wax baths, and ethyl chloride spray (Henry, 1964).

Surgical decompression of affected nerves was advocated by Muir (1948), Vaidyanathan and Vaidyanathan (1968), and Parikh, Ganapati and Kothare (1968) among others. These workers limited their decompression to exposure of the nerve trunk, and in the case of ulnar nerve, slitting of the fibrous arch covering the nerve at the back of the elbow. They reported varying degrees of success following surgery. On the other hand, Brand (1964) holds the view that operation on nerves is an unwise procedure, because surgical interference may cause further damage and subsequent fibrosis. Cochrane (1964) limited operations on nerves to cases of nerve abscess, when the nerve should be explored; for if, under those conditions, surgical interference is not initiated, gross damage may result-a damage far more crippling than that caused by any surgical interference.

This report is an assessment of the results of external and internal neurolysis of

\footnotetext{
* Received for publication 3 November, 1972.
} 
the ulnar and median nerves in leprous neuritis, carried out in the Department of Orthopaedic Surgery, Assiut University Hospital.

\section{Material and Methods}

The 36 patients who constituted the material of this study ( 31 male and 5 female) were selected at random; 30 of them had tuberculoid leprosy and 6 had the lepromatous type of the disease (Table 1). All of them had been on sulphone treatment for less than 1 year.

TABLE 1

Details of material

\begin{tabular}{|c|c|c|}
\hline & & $\begin{array}{l}\text { No. of } \\
\text { patients }\end{array}$ \\
\hline \multicolumn{2}{|l|}{ Total } & 36 \\
\hline \multirow[t]{2}{*}{ Sex } & Male & 31 \\
\hline & Female & 5 \\
\hline \multirow{2}{*}{ Type } & Tuberculoid & 30 \\
\hline & Lepromatous & 6 \\
\hline \multirow[t]{3}{*}{ Symptoms } & Pain & 36 \\
\hline & Sensory loss & 28 \\
\hline & Motor paralysis & 25 \\
\hline \multicolumn{2}{|c|}{ Ulnar n. neurolysis } & 30 \\
\hline & Bilateral & 17 \\
\hline \multicolumn{2}{|c|}{ Median $n$. neurolysis } & 4 \\
\hline \multirow{2}{*}{\multicolumn{2}{|c|}{$\begin{array}{l}\text { Combined ulnar and median } n \text {. neurolysis } \\
\text { E.M.G. study }\end{array}$}} & 2 \\
\hline & & 8 \\
\hline & Bilateral & 6 \\
\hline
\end{tabular}

The main complaint, common to all of them, was pain in the forearm and hand in the distribution of the affected nerve. The pain was in some cases severe enough to interfere with sleep and was not alleviated by analgesics or antiphlogistic measures. In 28 cases there was superficial sensory loss and 25 showed manifestation of motor deficit, in the form of atrophy of the forearm and/or hand muscles and deformity of the fingers characteristic of the affected nerve. Records were kept of the duration of pain, sensory charting, motor power, degree of atrophy of muscles, and the patients' own statements concerning ability to work. All these were noted before and after treatment.

Ulnar nerve neurolysis was performed in 30 cases (in 17 bilateral), median nerve neurolysis in 4, and ulnar and median nerve neurolysis in 2 (Table 2).

TABLE 2

Details of 36 cases of ulnar and/or median nerve neurolysis by type of disease

\begin{tabular}{lccccc}
\hline Type & $\begin{array}{c}\text { No. of } \\
\text { patients }\end{array}$ & $\begin{array}{c}\text { Ulnar n. } \\
\text { neurolysis }\end{array}$ & $\begin{array}{c}\text { Median n. } \\
\text { neurolysis }\end{array}$ & $\begin{array}{c}\text { Ulnar and median } \\
\text { n. neurolysis }\end{array}$ & Abscess \\
\hline Tuberculoid & 30 & 26 & 3 & 1 & 5 \\
$\begin{array}{c}\text { Lepromatous } \\
\text { Total }\end{array}$ & 6 & 4 & 4 & 1 & 5 \\
\hline
\end{tabular}


Electromyography was performed before and at varying intervals after the operation in 8 patients who had undergone ulnar nerve neurolysis (6 bilateral). Percutaneous stimulation of the ulnar nerve was made using two disc electrodes placed on the sides of the nerve in its superficial course in the upper arm. Muscle action potentials were recorded from the flexor carpi ulnaris by means of a bipolar needle electrode introduced into the muscle about $8 \mathrm{~cm}$ below the elbow. The electropotentials were recorded on a 6-channel "Physiograph". Electrical stimuli varying in frequency $(25,50$, and 100 per sec) and in voltage $(0.1$ to $25 \mathrm{~V})$ were used. The duration of the stimuli was constant in all the records $(2 \mathrm{~m} \mathrm{sec})$. Calibration was also constant throughout all records, in which $1 \mathrm{mV}$ was equal to $0.5 \mathrm{~mm}$. Two speeds for recording were used, $2.5 \mathrm{~cm}$ per sec and $5 \mathrm{~cm}$ per sec.

\section{Operative Technique}

A pneumatic tourniquet was applied to the upper part of the arm, unless this was impossible because the thickening of the nerve extended high up. The ulnar nerve was exposed from the middle of the arm to about the upper quarter of the forearm. The superficial and deep fascia and the medial intermuscular septum were incised to expose the nerve. The nerve was followed proximally until normal-looking nerve trunk was reached. Distally, the fibrous arch between the two heads of the flexor carpi ulnaris was slit, freeing the nerve in its course behind the elbow into the forearm.

In most of the cases the nerve trunk was oedematous and thickened, sometimes being as thick as a finger. Coursing on its surface were tortuous vessels of good size. In some cases the nerve trunk was fixed to its bed by dense adhesions. In 6 cases the nerve was found to be fibrosed, thinned, and ischaemic. The part of the nerve trunk deep to the divided arch was always thinner and paler than the proximal part of the nerve.

The nerve sheath and epineurium were then cut longitudinally. Using a sharp knife, a longitudinal cut was made into the substance of the nerve trunk between nerve bundles, taking great care not to go across any of the latter. This inter-bundle cut was deepened to about $2 / 3$ of the diameter of the nerve and extended along the whole affected segment. No attempt was made to dissect the nerve out of its bed, so as not to interfere with its blood supply, except in cases showing dense fibrous adhesions. The median nerve was exposed in the lower half of the forearm and into the hand, cutting the flexor retinaculum. It was treated in the same way.

Nerve abscess was encountered 5 times, 3 times in the ulnar and twice in the median nerve trunks. It was well encapsulated and fusiform in shape, reaching sometimes a length of up to $12 \mathrm{~cm}$. It was incised, and its contents, which were caseous in consistency, were scooped out. The wound was closed, and drainage maintained for $24 \mathrm{hrs}$.

\section{Results}

All the patients had complete relief of pain immediately after the operation. Of the 34 who were followed up for an average period of 17 months (ranging from 3 months to $3 \frac{1}{2}$ years), $31(91.2 \%)$ were free of pain at the time of follow-up. Of the 26 followed-up patients who had sensory changes before operation, 4 $(15.4 \%)$ had complete and $8(30.8 \%)$ had partial recovery of sensation. Of the 24 
who had shown impaired motor function before the operation $14(58.3 \%)$ showed complete or partial recovery of function. Details of the followed-up cases related to the duration of neuritis and nerve pathology encountered at operation are presented in Table 3.

TABLE 3

A verage duration of neuritis and post-operative results in 34 followed-up cases by nerve pathology

\begin{tabular}{|c|c|c|c|c|c|c|c|}
\hline \multirow[t]{2}{*}{ Nerve pathology } & \multirow[t]{2}{*}{ సٓ유 } & \multirow{2}{*}{ 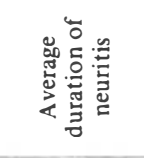 } & \multicolumn{2}{|c|}{ Type } & \multirow{2}{*}{ 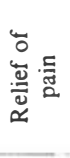 } & \multirow{2}{*}{ 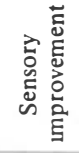 } & \multirow{2}{*}{ 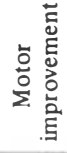 } \\
\hline & & & $\mathrm{T}$ & L & & & \\
\hline Oedematous and swollen \pm adhesions & 23 & 11 months & 17 & 6 & 23 & 9 & 12 \\
\hline Nerve abscess & 5 & 13 months & 5 & - & 5 & 2 & 2 \\
\hline Fibrosed and ischaemic & 6 & 3 years & 6 & - & 3 & 1 & - \\
\hline Total & 34 & & 28 & 6 & 31 & 12 & 14 \\
\hline
\end{tabular}

Eight patients had electromyographic records before the operation and at varying intervals after it; 6 underwent bilateral decompression of ulnar nerves. Out of the 14 decompressed nerves, $5(35.7 \%)$ showed marked improvement in muscle action potentials in post-operative E.M.G.'s (Figs 1, 4 and 5), $4(28.6 \%$ ) showed improvement (Fig. 2), in 2 (14.3\%) there was no change, and $3(21.4 \%)$ showed reduced action potentials (Fig. 3). There was almost no difference in the results for the two sides in the same patient. The results are presented in Table 4.

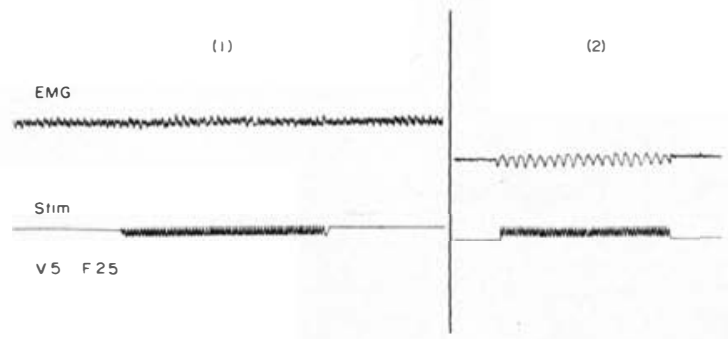

Fig. 1 Case 1, Table 4. E.M.G. before and after operation showing marked increase of amplitude.

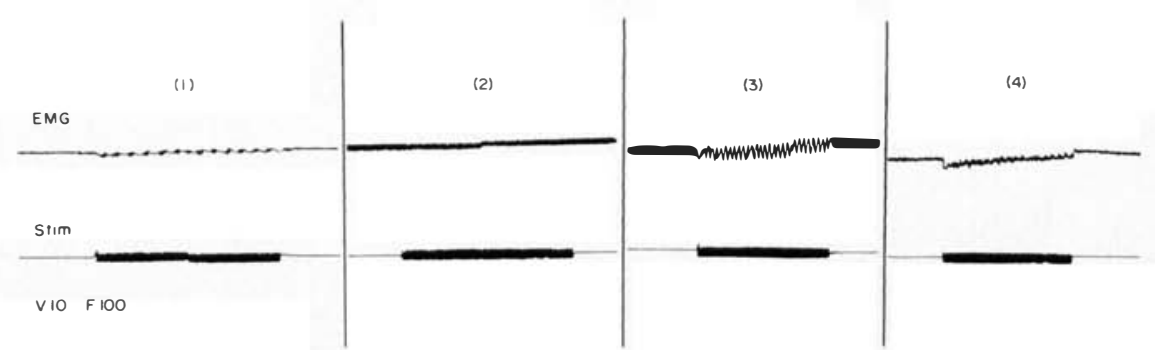

Fig. 2. Case 2, Table 4 comparing the post-operative records (2, 3 and 4$)$ with pre-operative record shows limited increase of amplitude, and regular waves. 

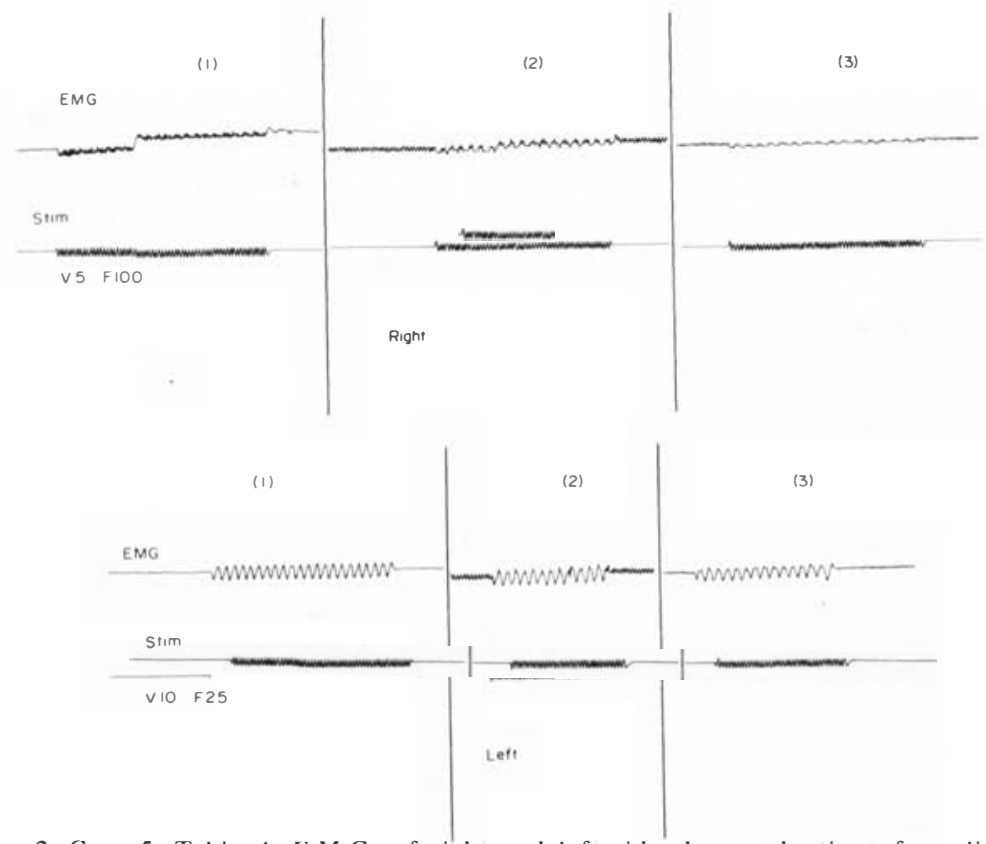

Fig. 3. Case 5, Table 4. E.M.G. of right and left side show reduction of amplitude. This result was graded "worse".

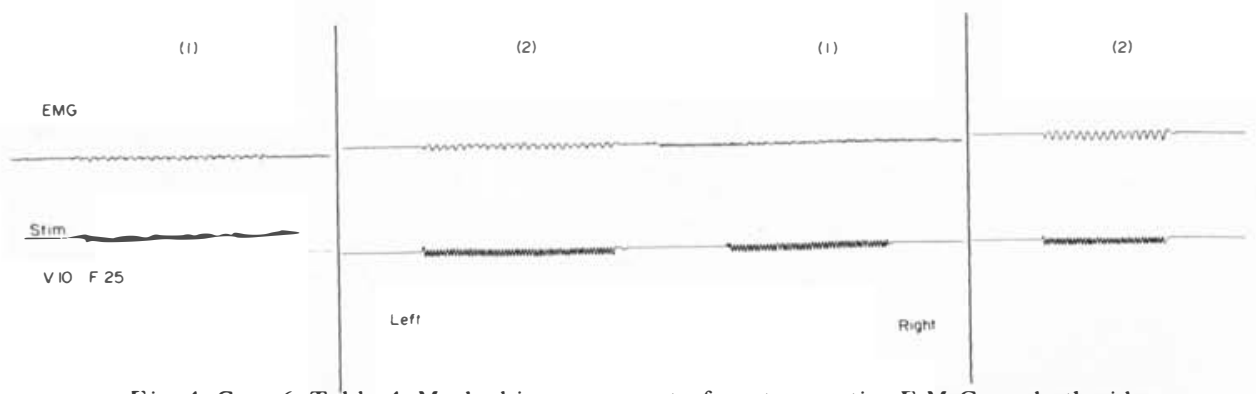

Fig. 4. Case 6, Table 4. Marked improvement of post-operative E.M.G. on both sides.

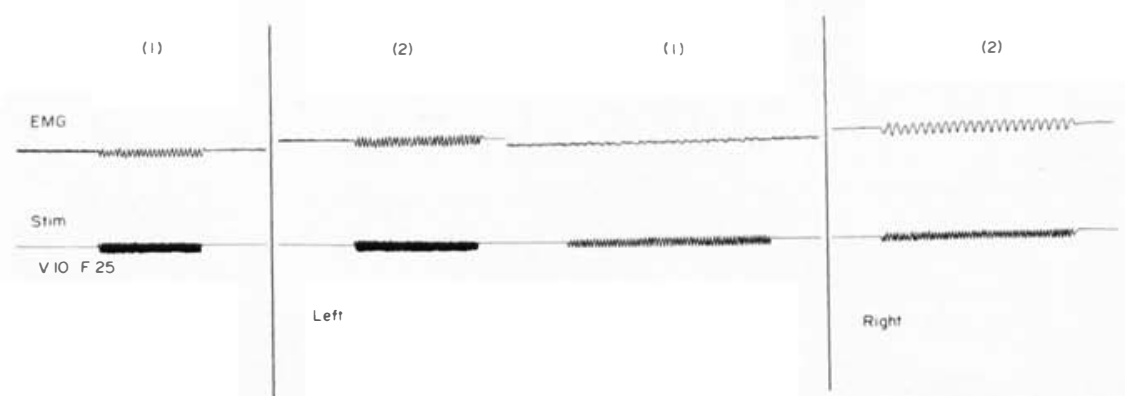

Fig. 5. Case 6, Table 4. Marked increase of amplitude and regular waves in post-operative tracing of right and left sides. 


\section{TABLE 4}

Change of amplitude of E.M.G. before and after operation in 8 cases (6 bilateral) related to nerve pathology

\begin{tabular}{|c|c|c|c|c|c|c|c|c|c|c|c|}
\hline \multirow{3}{*}{$\begin{array}{l}\text { Case no. } \\
\text { and side }\end{array}$} & \multirow{3}{*}{ Type } & \multicolumn{8}{|c|}{ Amplitude of E.M.G. in M.V. } & \multirow{3}{*}{ Comment } & \multirow{3}{*}{ Nerve pathology } \\
\hline & & \multicolumn{2}{|c|}{$\begin{array}{c}\text { Record } 1 \\
\text { (Before op.) }\end{array}$} & \multicolumn{2}{|c|}{$\begin{array}{c}\text { Record } 2 \\
\text { (Within } 1 \text { month) }\end{array}$} & \multicolumn{2}{|c|}{$\begin{array}{c}\text { Record } 3 \\
\text { (3 months) }\end{array}$} & \multicolumn{2}{|c|}{$\begin{array}{c}\text { Record } 4 \\
\text { (12 months) }\end{array}$} & & \\
\hline & & B.S. & A.S. & B.S. & A.S. & B.S. & A.S. & B.S. & A.S. & & \\
\hline $1 \mathrm{Rt}$ & $\mathrm{T}$ & 5 & 7 & 1 & 8 & - & - & - & - & Much improved & Hyperaemic and swollen \\
\hline $2 \mathrm{Lt}$ & $\mathrm{T}$ & 1 & 2 & 3 & 3 & 5 & 10 & 2 & 5 & Improved & Nerve abscess \\
\hline $3 \mathrm{Rt}$ & $\mathrm{T}$ & 3 & 3 & 3 & 4 & & - & 2 & 2 & Same & Oedematous swollen and \\
\hline $3 \mathrm{Lt}$ & $\mathrm{T}$ & 3 & 4 & 4 & 4 & - & - & 2 & 4 & Improved & adherent \\
\hline $4 \mathrm{Rt}$ & $\mathrm{T}$ & 1 & 4 & 4 & 6 & - & - & 1 & 2 & Worse & Fibrosed, thin and \\
\hline $4 \mathrm{Lt}$ & $\mathrm{T}$ & 1 & 1.0 & 4 & 11 & - & - & $\begin{array}{l}1 \\
1\end{array}$ & 8 & Worse & ischaemic \\
\hline $5 \mathrm{Rt}$ & $\mathbf{L}$ & 1 & 6 & 4 & 10 & - & - & - & & Improved & Oedematous and \\
\hline $5 \mathrm{Lt}$ & $\mathrm{L}$ & 1 & 10 & 3 & 13 & - & - & - & & Improved & swollen \\
\hline $6 \mathrm{Rt}$ & $\mathrm{T}$ & 1 & 2 & 0.5 & 6 & - & _ & - & & Much improved & Oedematous swollen and \\
\hline $6 \mathrm{Lt}$ & $\mathrm{T}$ & 1 & 3 & 0.5 & 4 & - & - & - & - & Much improved & hyperaemic \\
\hline $7 \mathrm{Rt}$ & $\mathrm{T}$ & 4 & 12 & - & & & _- & 3 & 6 & Worse & Fibrosed and \\
\hline $7 \mathrm{Lt}$ & $\mathrm{T}$ & 4 & 9 & - & - & - & - & 3 & 5 & Same & ischaemic \\
\hline $8 \mathrm{Rt}$ & $\mathrm{T}$ & 1 & 3 & $\overline{1}$ & 8 & & & & - & Much improved & Hyperaemic and \\
\hline $8 \mathrm{Lt}$ & $\mathrm{T}$ & 1 & 5 & $\begin{array}{l}1 \\
1\end{array}$ & 6 & - & - & - & - & Much improved & swollen \\
\hline
\end{tabular}

T, tuberculoid; L, lepromatous; B.S., before stimulation; A.S., after stimulation. 


\section{Discussion}

Leprosy is primarily a disease of nerves. The lepra bacillus lodges in the axoplasm of nerve fibres, which as a result of metabolic activity of the organism undergoes degenerative changes. The myelin sheath also undergoes disintegration. The collapsed Schwann tubes are converted into ribbon-like bands. The bacilli find shelter in these bands and in the cytoplasm of the Schwann cells. The bacilli which escape from the nerve fibres are taken up by the endoneural cells and histiocytes. The latter change gradually into lepra cells or epithelioid cells in the endo- and perineural spaces, depending on the difference in the immunological response of the host (Khanolkar, 1964).

Aggregation of this cellular infiltration in the endo- and peri-neural space, in addition to oedema, results in swelling of the nerve and compression of the nerve fibres, as well as relative ischaemia inside the nerve. There may be plenty of blood vessels in the nerve sheath and epineurium, but inside the nerve itself the blood vessels are very few.

Partial ischaemia causes a reversible paralysis without Wallerian degeneration. If, however, the ischaemia becomes absolute or lasts for a long time, the nerve will be destroyed and the paralysis is then irreversible.

Sometimes localized areas of autolysis occur in a peripheral nerve trunk, forming what is called a nerve abscess. In such cases the nerve is greatly thickened and tender and contains masses of necrotic debris and sloughs. Rapid deterioration of nerve function and destruction of its fibres depend upon the amount of the abscess contents as well as on its long-standing tension inside the nerve. It is presumably an allergic localized autolysis of the nerve trunk at certain well-defined sites (Browne, 1965). In certain places, for instance in Calcutta, nerve abscesses are more common than elsewhere in India (Cochrane, 1964). Wheate (1964) and Browne (1965) drew attention to the rarity of nerve abscesses in Africa. However, Priestman (1966) found 7 patients with nerve abscesses within 4 years in Nigeria. Among our patients in this study, 5 abscesses were encountered. So it would seem that nerve abscesses in certain places in Africa are not as rare as generally believed.

The commonly affected motor nerves in leprosy are the ulnar nerve just above the elbow and just above the wrist, the median nerve just above the wrist, the lateral popliteal nerve at the knee, the posterior tibial nerve about $10 \mathrm{~cm}$ above the ankle, and, rarely, the radial nerve just above the elbow (Brand, 1964; Said, 1971).

Brand (1964) maintains that there are three main factors which determine whether a nerve infected by lepra bacilli becomes paralysed or not: (1) Type of the disease: the tuberculoid type, with strong tissue reactivity, is the commonest type in which selected nerves are paralysed. In the lepromatous type the tissue reaction is weak and therefore the chance of nerve damage is small. (2) The number of nerve fibres which are enclosed in the epineurium of the nerve: the greater the number of nerve fibres within the bundle, the greater is the likelihood of paralysis. (3) The perpendicular distance from the surface of the body: the greater the distance from the surface, the smaller is the chance of paralysis.

External neurolysis can relieve the nerve from external pressure, but the interior of the nerve, which is the part actually suffering from compression and ischaemia, is left as it is. Parikh, Ganapati and Kothare (1968), adopting this technique, found the progressive paralysis unchecked by decompression in about $25 \%$ of their cases because "only the external pressure on the individual nerve was relieved and the nerve fibres themselves were not subjected to any 
interference during surgery". The only way to decompress the interior of the nerve is to slit it longitudinally between the nerve bundles, as performed in our patients in this study.

Our results of external and internal neurolysis were gratifying in that the intractable pain was relieved in $91.2 \%$ of followed-up patients, a fact which could change the whole mental and spiritual state of the individuals; $58.3 \%$ of the patients showed complete or partial clinical improvement of motor function postoperatively. Of the cases studied by electromyography $64.3 \%$ showed improvement after the operation. Sensory improvement occurred in $46.2 \%$ of cases. In none of the cases was there clinical deterioration of nerve function after operation. The best results were obtained in patients in whom the nerve trunk at operation was oedematous, swollen and surrounded by a hyperaemic sheath, especially so if not stuck by adhesions to its bed. On the other hand, fibrosed, thinned and ischaemic nerves showed the least improvement after surgery. Thus the results of external and internal neurolysis depend primarily on the nerve pathology at the time of surgery and not on whether damage to nerve fibres at operation occurred. Further evidence for this statement is the fact that cases operated upon bilaterally, and showing the same pathology, also showed almost equal results on the two sides.

The results presented in this report compare favourably with those of other workers performing external neurolysis only (Vaidyanathan and Vaidyanathan (1968) and Parikh, Ganapati and Kothare, 1968). However, comparison of different surgical techniques in different countries is not practical as the pathology of leprous neuritis varies from place to place, as mentioned above.

\section{Acknowledgement}

We wish to thank Dr Dia Abdel-Rehim, Assistant Professor of Dermatology, for allowing us access to leprosy patients attending the Skin Clinic, Assiut University Hospital, and for assistance in following-up the cases.

\section{References}

Brand, P. W. (1964). Deformity in Leprosy. Leprosy in Theory and Practice, 2nd ed. (Ed. R. G. Cochrane and T. F. Davey), pp. 447-494. Bristol: John Wright and Sons Ltd.

Browne, S. G. (1965). Nerve abscesses in African Leprosy. Lepr. Rev. 36, 55-57.

Cochrane, R. G. (1964). Neuritis in leprosy. Leprosy in Theory and Practice, 2 nd ed. (Ed. R. G. Cochrane and T. F. Davey), pp. 410-417. Bristol: John Wright and Sons Ltd.

Henry, D. E. (1964). A new and simplified technique of treating, acute neuritis in leprosy using ethyl chloride spray. Lepr. Rev. 35, 103-105.

Jennings, W. H. (1964). Effect of injection of hydrocortisone into nerves thickened by leprosy. Lepr. Rev. 35, 83-85.

Khanolkar, V. R. (1964). Pathology of Leprosy. Leprosy in Theory and Practice, 2 nd ed. (Ed. R. G. Cochrane and T. F. Davey), pp. 125-151. Bristol: John Wright and Sons Ltd.

Muir, E. (1948). Manual of Leprosy. Edinburgh: E. \& S. Livingstone Ltd. pp.137-138.

Parikh, A. C., Ganapati, R. and Kothare, K. B. (1968). Decompression of ulnar and median nerves in leprous neuritis. Lepr. Rev. 39, 143-146.

Priestman, F. G. (1966). Nerve abscesses in Northern Nigeria, Lepr. Rev. 38, 35-36.

Said, G. Zaki (1971). Leprosy. Orthopedic Surgery, 1st ed. (Eds K. El-Zorkani and S. Gado), pp. 66-71. Cairo: Dar Al-Maaref.

Tio, T. H. (1966). Neural involvement in leprosy. Treatment with intraneural injection of prednisolone. Lepr. Rev. 37, 93-97.

Vaidyanathan, E. P. and Vaidyanathan, S. I. (1968). Treatment of ulnar neuritis and early ulnar paralysis. Lepr. Rev. 39, 217-222.

Wheate, H. W. (1964). T wo unusual cases of nerve abscesses. Lepr. Rev. 35, 86-87. 